\title{
Mechanical Properties of Soft Rocks Subjected to Water-Rock Reaction and Cyclic Pressure
}

\author{
Wei Huang $\mathbb{D},{ }^{1}$ Rui Feng, ${ }^{2}$ Huanran Fu, ${ }^{1}$ Jingyu Chen, ${ }^{1}$ and Zili Feng ${ }^{1}$ \\ ${ }^{1}$ Civil Aviation Flight University of China, Guanghan 618307, China \\ ${ }^{2}$ Military Facilities Engineering Service Center, Southwest Exploration and Design Institute of Nuclear Industry, \\ Chengdu 610065, China \\ Correspondence should be addressed to Wei Huang; huangwei@cafuc.edu.cn
}

Received 24 July 2021; Revised 8 December 2021; Accepted 31 January 2022; Published 23 February 2022

Academic Editor: Yanbin Luo

Copyright (C) 2022 Wei Huang et al. This is an open access article distributed under the Creative Commons Attribution License, which permits unrestricted use, distribution, and reproduction in any medium, provided the original work is properly cited.

\begin{abstract}
Studying the mechanical properties of soft rocks subjected to water and cyclic loading would contribute to a better understanding of the stability analysis of soft rock engineering under the conditions of storm and carrier dynamics. In this paper, two soft rocks from Southwest China (i.e., muddy siltstone and silty mudstone) were selected as test samples. Uniaxial compressive tests were applied to investigate the strength and deformation characteristics under water-rock reactions. Meanwhile, triaxial tests were carried out to analyse the fatigue damage and failure characteristics by applying cyclic axial loading under different confining pressures. The results indicated a reduction in the uniaxial compressive strength (UCS) under saturated conditions, which is correlated with the disintegration resistance of soft rocks. Moreover, the samples exhibited a softening phenomenon due to water absorption and rock expansion, decreasing the elastic modulus. The triaxial tests demonstrated that axial strain accumulated with the number of loading cycles due to fatigue and even failed when applying increased cyclic loading with certain cycles. The cohesion decreased during cyclic loading, but the friction angle was relatively independent of the number of cycles. In addition, reductions in the dynamic elastic modulus and shear modulus decreased with increasing loading time. This study indicated that water and cyclic loadings could cause significant degradation of the strength and stiffness of soft rocks, which need to be considered carefully during the engineering utilization of such materials.
\end{abstract}

\section{Introduction}

As a common geotechnical material, soft rocks, which cause prominent engineering geology problems, are widely distributed in Southwest China. The soft rock is integral, exhibits considerable mechanical strength in its natural state, and has been selected as a backfill subgrade material. However, this material softens easily or even collapses after the impact of water [1-3]. Consequently, the mechanical properties are obviously reduced, significantly influencing the safety of engineering facilities such as expressways, highspeed railways, and airport runways $[4,5]$.

Research on water-rock interactions has been a very popular topic because the results have important guiding significance for engineering safety. The most intuitive results of these studies showed that the mechanical strength of the rock produces a significant reduction due to the presence of water [3, 6-10]. Moreover, how water weakens rocks has also been investigated to explain the intrinsic drive of water-rock interactions. The transformation of the microstructure of soft rock under saturated conditions was recognized to be the main cause of its strength degradation [11-14]. Furthermore, the microstructural changes are related to the content of clay minerals. However, research on the waterrock reaction mechanism is detailed and complex work that needs to investigate the influence of the type, hydration properties, and expansive behaviours of clay minerals on the microstructure of soft rock. It was not enough to explain the mechanism of the water-rock reaction by only the content of clay minerals, and more meticulous work needs to be performed to study the interaction between water and soft rock. Alternatively, a parameter that comprehensively 
characterized the mineral properties of soft rocks could be selected to explore the strength damage of the soft rock. Therefore, the water content was used as such a parameter, and rheological models were derived, considering the water damage $[15,16]$. These types of models described the creep damage evolution process of soft rock under the time effect, considering the long-term water-rock interaction, which could predict the long-term stability of engineering facilities. However, in engineering practice, especially under heavy rainfall conditions, destabilization of various types of rock masses occurs mostly in a short period of time, such as rapid swelling, softening, and disintegration of clay rocks after water exposure. To realize the application of the conclusion of the water-rock reaction in engineering construction, analysis of the properties of soft rocks in contact with water needs to be easy and realistic. For this purpose, the analysis of soft rock swelling and disintegration, which are physical properties directly related to the water absorption and deformation characteristics of soft rock, and the proposed strength damage model of soft rock will accordingly provide a new way of thinking for the degradation analysis of soft rock.

In recent years, with the vigorous promotion of infrastructure construction work on highways, high-speed railroads, and airports in Southwest China, the cyclic loading generated by the corresponding traffic carriers is a factor that cannot be ignored and has an important influence on engineering safety in soft rock areas [17-19]. Consequently, in addition to the effect of water on the strength of soft rocks, attention should also be paid to the possible effect of cyclic loading on soft rocks to avoid potential engineering risks. At present, many studies have been conducted on the dynamic properties of rocks; e.g., the deformation characteristics, mechanical strength, and fatigue damage under cyclic loading have been discussed in [18, 20-22]. Early research efforts have focused on the deformation and failure behaviour of rock under cyclic loading, stating that cyclic loading can significantly reduce the strength and stiffness of materials and lead to an accumulation of strains [20, 23]. Meanwhile, fatigue, known as the tendency of materials to failure due to cyclic loading [24], was also a theme that attracted much attention from scholars. The fatigue mechanism was hence investigated, and it was important in the field of earthquake and mining engineering. Nevertheless, this mechanism might be unsuitable in foundation design because the factors affecting the fatigue mechanism of rock are markedly different, including loading factors, rock factors, and environmental factors [21]. Especially for soft rock, a sensitive microstructure exists $[11,12,20]$, and its deformation characteristics and mechanical strength under cyclic loading could obviously be different from those of common rocks. Thus, this paper intends to study the mechanical characteristics of soft rock subjected to cyclic loading in the field of foundation engineering.

In the current study, the main objective was to discuss the effects of water and cyclic loading on the deformation characteristics and mechanical strength of soft rocks in Southwest China. Subsequently, the effect of water is discussed based on the results, and a prediction model for hydrogenic damage in soft rocks is proposed. Finally, the boundary state of fatigue damage and the fatigue mechanism are comprehensively discussed. The hypothesis is that the results and conclusion could provide useful references for the stability evaluation of soft rock projects under the action of storm and carrier dynamics.

\section{Materials and Methods}

2.1. Experimental Materials. The soft rocks used in this study were muddy siltstone and silty mudstone of the lower group of the Guankou Formation $\left(\mathrm{K}_{1} \mathrm{~g}^{1}\right)$, taken from an engineered slope of a low- and intermediate-level radioactive waste disposal project in Sichuan Province, China. Rainfall is an important factor for the stability of slopes and the security of disposal sites. These two kinds of rocks are also widely used as backfill subgrade materials in airports, such as the Nanchong, Bazhong, and Luzhou airports located in the Sichuan Basin. Obvious postconstruction settlement deformation of the runway under carrier loading appeared in these airports because of the mechanical property changes associated with such soft rocks. Therefore, these two types of rocks were tested for their potential applications for a new specific site or a project (i.e., airport subgrade and slope of nuclear waste disposal site). The physical parameters of the rock samples were measured, and their average values are given in Table 1. The muddy siltstone is composed of quartz, feldspar, rock chips, calcite, clay, and other minerals, including clay content of $17 \%-19 \%$, and the silty mudstone is composed of sericite, quartz, calcite, clay, and other minerals, in which the clay content is $21 \%-25 \%$. The clay minerals in the two soft rocks were mainly montmorillonite and hydromica, which are highly hydrophilic and dominate the characteristics of the rocks to swell and disintegrate when they encountered water, as shown in Table 2.

\subsection{Uniaxial Compressive Strength and Deformation Test.} The uniaxial compressive strength and compressive deformation tests of two soft rocks were carried out using the MTS 815 rock testing system (MTS Testing Industries, Eden Prairie, MN, USA). The test procedure was controlled by axial displacement, and the loading speed was $0.1 \mathrm{~mm} / \mathrm{min}$. Natural and saturated rock samples taken from the same rock mass with similar initial structural characteristics and mechanical properties were selected to measure the mechanical and deformation properties. In this case, the saturated rock samples were saturated for 24 hours using the vacuum pumping method.

2.3. Slake Durability Test. The slake durability index of the two soft rocks was measured by an XYN-1 slake durability tester (XINYU instrument, Taizhou, Jiangsu, China). In the test, the specimens were placed into a drum and then dried at $105^{\circ} \mathrm{C}-110^{\circ} \mathrm{C}$ until no mass change was observed. The drum with soft rock is mounted in the trough and coupled to the motor. The trough is filled with distilled water at room temperature to a level $20 \mathrm{~mm}$ below the drum axis. The drum was rotated at $20 \mathrm{rpm}$ for a period of $10 \mathrm{~min}$ and then dried 
TABLE 1: Average physical parameters of soft rocks.

\begin{tabular}{lccccc}
\hline Soft rock & $\begin{array}{c}\text { Water content }(\omega) \\
(\%)\end{array}$ & $\begin{array}{c}\text { Natural density }\left(\rho_{0}\right) \\
\left(\mathrm{g} / \mathrm{cm}^{3}\right)\end{array}$ & $\begin{array}{c}\text { Saturation density }\left(\rho_{\mathrm{w}}\right) \\
\left(\mathrm{g} / \mathrm{cm}^{3}\right)\end{array}$ & Specific gravity $(\mathrm{Gs})$ & Statistical quantity \\
\hline Muddy siltstone & 3.82 & 2.50 & 2.51 & 2.74 & 11 \\
Silty mudstone & 5.91 & 2.48 & 2.47 & 2.74 & 10 \\
\hline
\end{tabular}

TABLE 2: Disintegration resistance index and expansion rate of soft rocks.

\begin{tabular}{lcc}
\hline Soft rock & Muddy siltstone & Silty mudstone \\
\hline Disintegration resistance index (\%) & 86.01 & 78.52 \\
Free swelling rate (\%) & 7 & 19 \\
Expansion force $(\mathrm{kPa})$ & 0 & 0.22 \\
Water saturated absorptivity of rock (\%) & 4.92 & 5.72 \\
\hline
\end{tabular}

with the specimen retained in the oven at the same temperature to determine the oven-dried mass. Last, the above slaking process was repeated for a second cycle to calculate the slake durability index.

2.4. Triaxial Test with Cyclic Loading. The natural state rock sample was placed into MTS 815 to measure the dynamic mechanical properties by triaxial tests with cyclic loading. This test was carried out based on applying axial and lateral confining pressure to the rock specimen. In the testing process, the confining pressure remained constant, and then cyclic loading with axial equal amplitude was applied. The stress condition was simulated by keeping the confining pressure $\sigma_{3}$ constant and then applying an axial static load $\sigma_{1}$, the size of which was taken as $\sigma_{3}+1 / 2 \sigma_{\mathrm{d}}$, where $\sigma_{\mathrm{d}}$ was the amplitude of the cyclic loading. The loading mode was loadcontrolled, with a loading speed of $15 \mathrm{kN} / \mathrm{min}$ for axial loading, and the loading stopped when the axial stress reached $\sigma_{1}$. On this basis, the axial static load $\sigma_{1}$ was used as the vibration centre value, and $1 / 2 \sigma_{\mathrm{d}}$ was used as the amplitude to apply load to rock samples. As for the value of amplitude, it was as the one that could help investigate the influence of axial load in triaxial test with cyclic loading and boundary axial load which caused the failure of soft rock so that several values of amplitude were taken as test parameters in a certain confining load condition. In this test, the confining pressure was taken as $0,1.5$, and $3 \mathrm{MPa}$, and estimated axial loads are selected into Table 3 . The frequency was defined based on the main frequency of irregular vibration generated by traffic load acting on the foundation, which generally ranges from 0.5 to about $5 \mathrm{~Hz}$. In this research, $1 \mathrm{~Hz}$ was selected as loading frequency which was similar to the previous report $[25,26]$.

\section{Results}

3.1. Rock Degradation Subjected to Water. The stress-strain curves of uniaxial compressive strength tests for natural and saturated rock samples are given in Figure 1, displaying the stress in the natural rock sample decreasing rapidly after reaching the peak strength, which demonstrated an obvious brittle characteristic. In contrast, the stress in the saturated sample decreased more slowly than the stress in the natural
TABlE 3: Test parameters in triaxial test with cyclic loading.

\begin{tabular}{lcccccccc}
\hline$\sigma_{3}(\mathrm{MPa})$ & \multicolumn{6}{c}{$\begin{array}{c}\text { Estimated amplitude } \sigma_{\mathrm{d}} \\
(\mathrm{MPa})\end{array}$} & Loading mode & $\begin{array}{c}\text { Frequency } \\
(\mathrm{Hz})\end{array}$ \\
\hline 0 & 10 & 12 & 14 & 16 & 18 & 20 & Load- & \\
1.5 & 20 & 24 & 28 & 32 & 36 & 40 & controlled & 1 \\
3 & 42 & 44 & 46 & 48 & 52 & 55 & & \\
\hline
\end{tabular}

sample after reaching the peak with a prominent strainsoftening phenomenon, indicating that water had a softening effect on both soft rocks. In addition, the peak compressive strength of the saturated rock samples was significantly lower than the peak compressive strength of the natural samples, which decreased from $25.76-21.35 \mathrm{MPa}$ to 17.04-7.07 MPa for muddy siltstone and from 17.65-9.94 MPa to $11.3-5.59 \mathrm{MPa}$ for silty mudstone. As mentioned previously, the initial structural characteristics and mechanical properties of the two-state rock samples were similar. Thus, we could assume that the mechanical properties of muddy siltstone and silty mudstone were degraded by water.

3.2. Rock Degradation Subjected to Cyclic Loading. The degradation processes of muddy siltstone and silty mudstone were studied according to the experimental method described previously and are shown in Figures 2 and 3. The figures illustrate the curves of axial accumulated strain $\varepsilon_{\mathrm{d}}$ with the number of cyclic loadings $\mathrm{N}$ for different combinations of confining pressures with the dynamic load. The results showed that the axial accumulated strain tended to be stable or increased slowly after 2000 loading cycles, indicating that some rock samples did not fail at this time, and the effect of cyclic loading on the soft rock was only a small amount of plastic deformation. Furthermore, when the applied cyclic loading $\sigma_{\mathrm{d}}$ increased, $\varepsilon_{\mathrm{d}}$ gradually became larger. Then, after the loading times exceeded a certain limit, $\varepsilon_{\mathrm{d}}$ changed abruptly and increased steeply, finally resulting in the failure of the rock samples. The results of damaged samples indicated that cyclic loading first produced fatigue damage to the soft rock, resulting in plastic deformation of the sample, and with the increasing number of loading times, the resulting fatigue damage gradually accumulated. When 


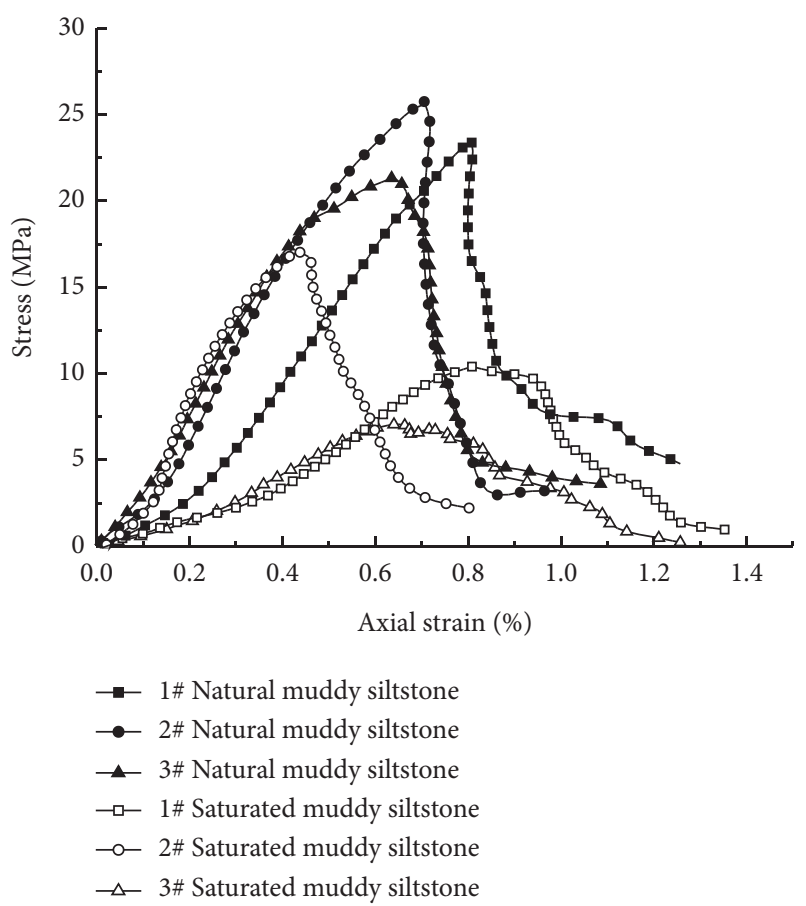

(a)

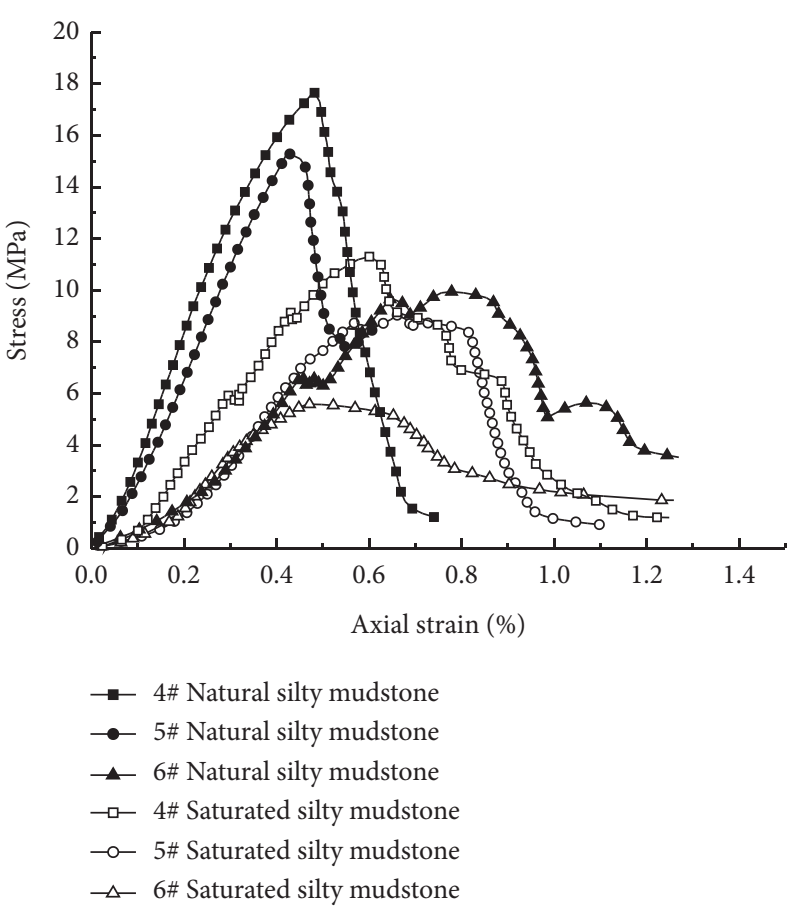

(b)

FIGURE 1: Stress-strain curves through the uniaxial compressive strength (UCS) test: (a) muddy siltstone; (b) silty mudstone.

the accumulated damage reached a certain amount of soft rock, rock failure occurred. As we concluded, with the same circumferential pressure $\sigma_{3}$, the rock sample gradually progressed from undamaged to failing as the cyclic loading $\sigma_{\mathrm{d}}$ increased, demonstrating that the applied cyclic loading was the key to conducting the occurrence of failure in the rock sample.

\section{Discussion}

4.1. Damage Effect of Water on Soft Rocks. The origin of mechanical property damage of soft rocks under water action could be analysed in terms of the mineral composition of the rock as well as structural characteristics. As mentioned in the Introduction, the strength damage of soft rocks was rooted in their internal structural adjustment $[11,12,14]$. The results of these studies also pointed out that soft rocks provided transport channels in the microstructure for water to enter the interior of the rock. The mineral identification results showed that there were $17 \%-19 \%$ and $21 \%-25 \%$ mass percentages of hydrophilic clay minerals in the muddy siltstone and silty mudstone, respectively. The water molecules entering the pore structures would interact with the clay particles, and water absorption and swelling would occur, resulting in some of the rock particles disintegrating and flaking off, finally leading to internal structure changes and strength reduction of rock [27].

Since soft rocks exhibit mechanical property damage due to the disintegration of rock particles under the action of water, there should be some correspondence between the disintegration characteristics of rocks and their mechanical strength changes. Therefore, the correspondence between the disintegration characteristics and the mechanical strength is given in Figure 4, where the disintegration characteristic is portrayed using the slake durability index [28], while the mechanical strength is characterized by the ratio of the saturation compressive strength $\sigma_{\mathrm{cs}}$ to the natural compressive strength $\sigma_{\mathrm{c}}$. As shown in Figure 4, there was a good linear relationship between the two variables, and the correlation coefficients were 0.9433 and 0.9471 for muddy siltstone and silty mudstone, respectively, after fitting the rocks, which verified the mechanism of water damage to rocks discussed in the previous section, and the strength damage $D_{W}$ of rocks by water could be quantified and characterized by the disintegration resistance index; see Equations (1) and (2).

$$
\text { muddy siltstone }: \begin{aligned}
D_{W} & =1-\frac{\sigma_{c s}}{\sigma_{c}} \\
& =1-\frac{\mathrm{a}-0.6108}{0.4025}, \\
\text { silty mudstone }: D_{W} & =1-\frac{\sigma_{c s}}{\sigma_{c}} \\
& =1-\frac{\mathrm{a}-0.5254}{0.4861}
\end{aligned}
$$

Furthermore, Equations (1) and (2) could also be used to predict the strength decay characteristic of this type of soft rock under storm conditions and provide the corresponding parameter for the safe design of soft rock projects.

As mentioned above, the two rocks softened under the action of water. Hence, their deformation characteristics would also be clearly related to the action of water. Based on 


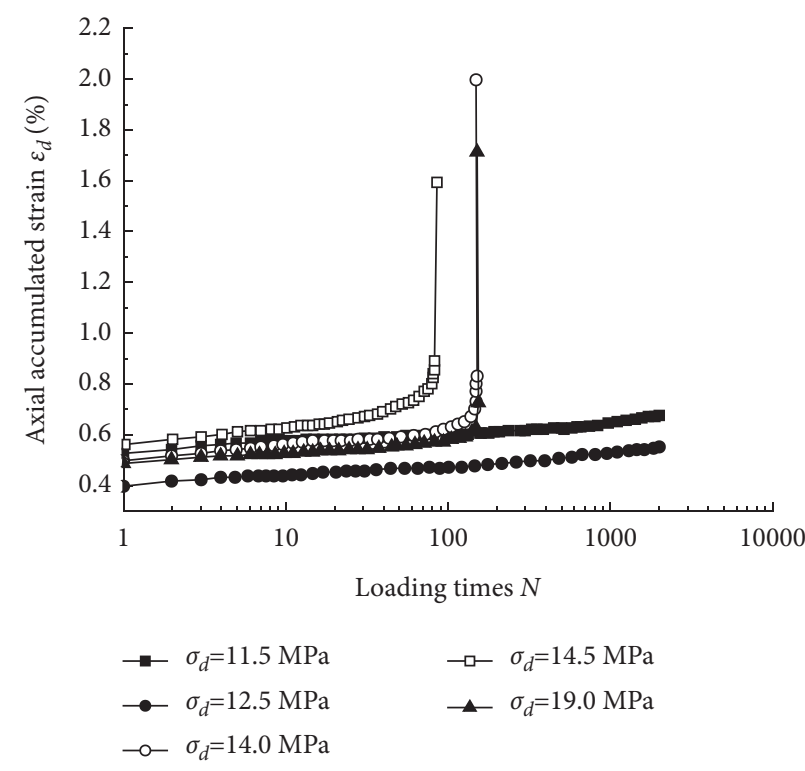

(a)

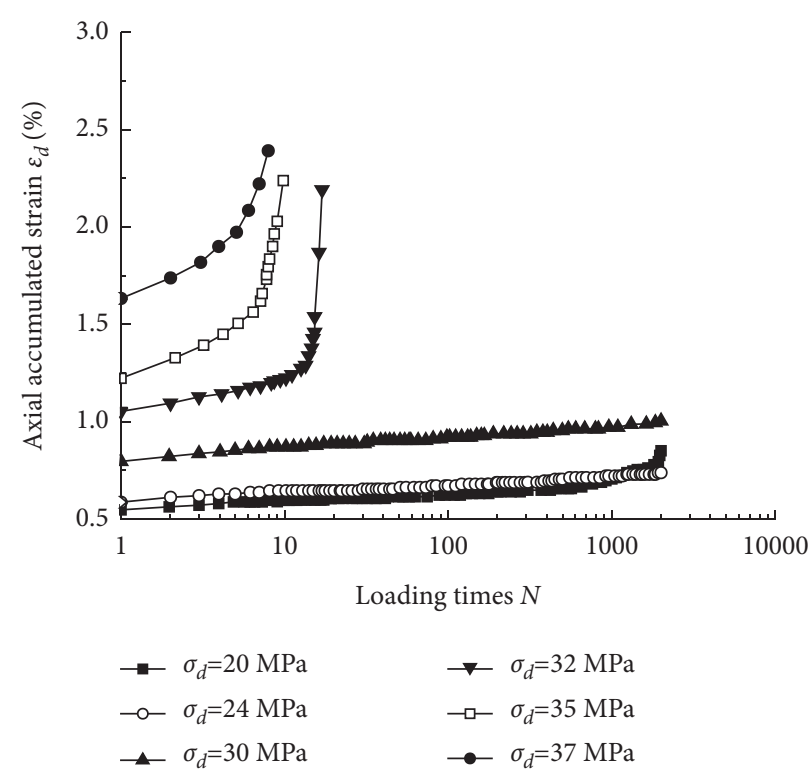

(b)

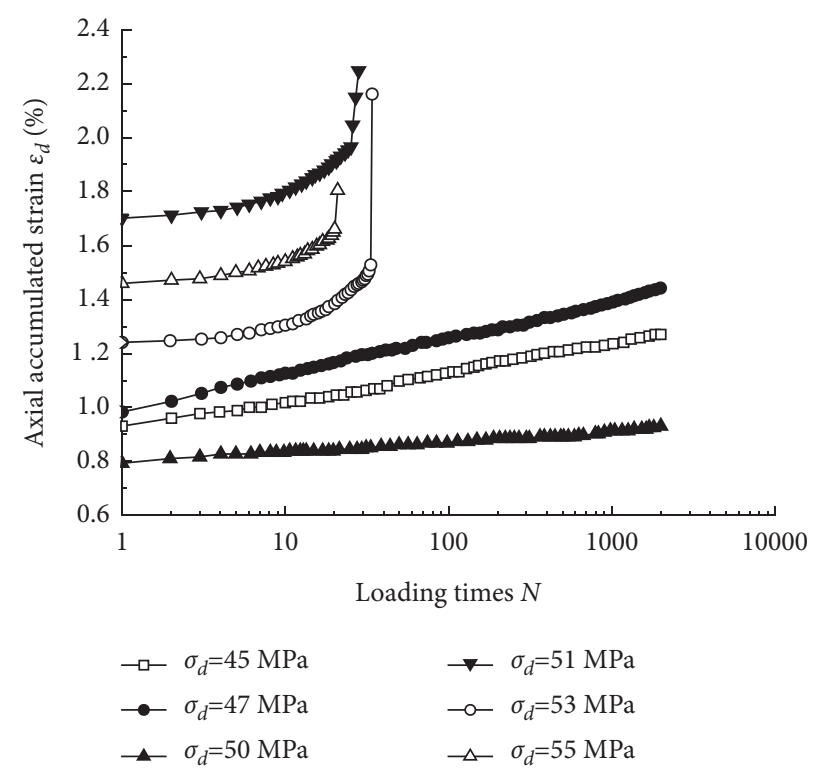

(c)

Figure 2: Degradation of muddy siltstone under cyclic loading: (a) $\sigma_{3}=0 \mathrm{MPa}$; (b) $\sigma_{3}=1.5 \mathrm{MPa}$; (c) $\sigma_{3}=3 \mathrm{MPa}$.

the test, both the muddy siltstone and the silty mudstone swelled at different scales when interacting with water, which could be considered an objective manifestation of the deformation of soft rocks. Furthermore, the stress-strain curves of the two rocks softened by water in Figure 1 were significantly different from the stress-strain curves of the natural rocks in the process of deformation under pressure, and the corresponding elastic modulus was reduced. Consequently, rock swelling that reflects the objective expression of the deformation characteristics and elastic modulus, which are theoretical parameters indicating the deformation characteristics of soft rock, should have a mutual connection. To explore the interrelationship between the two, the relationship curve was made with the free swelling rate $b$ and the ratio of the modulus of elasticity $E_{s}$ of saturated rock samples to the modulus of elasticity $E$ of natural rock samples, which is shown in Figure 5. Although $b$ and $E_{s} / E$ did not show a perfect linear relationship, the trend showed that $E_{s} / E$ decreased as the free swelling rate increased, indicating that the modulus of elasticity of saturated rock samples decreased, reflecting the softening of rocks in the water and showing plastic deformation characteristics.

4.2. Mechanical Damage of Soft Rock under Cyclic Loading. The axial loading of $\sigma_{\mathrm{d}}$ that led to a final failure was selected and is displayed in Table 4, showing that confining pressure was an important parameter affecting the mechanical 


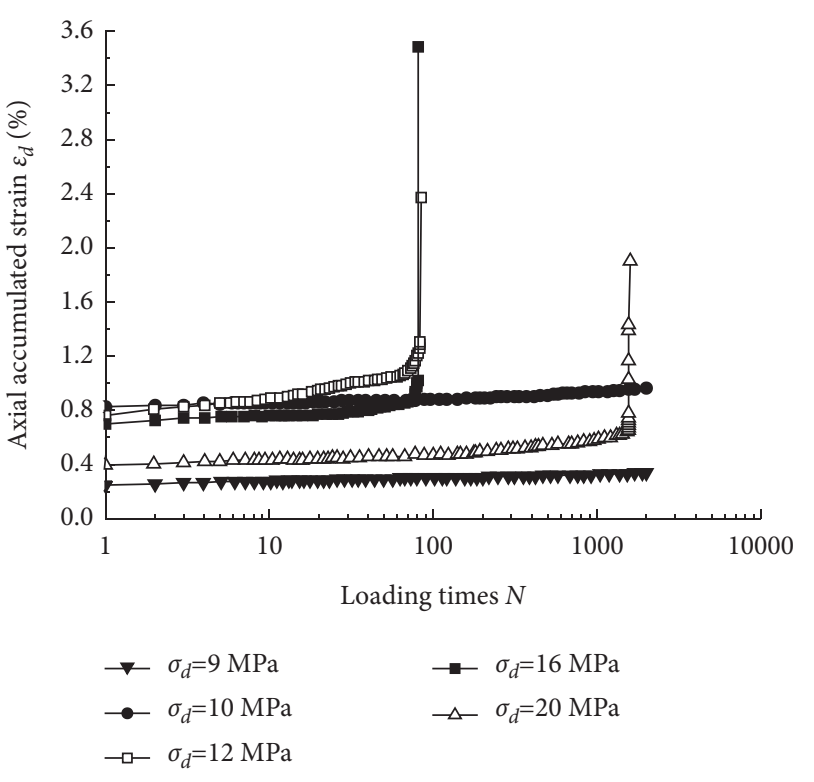

(a)

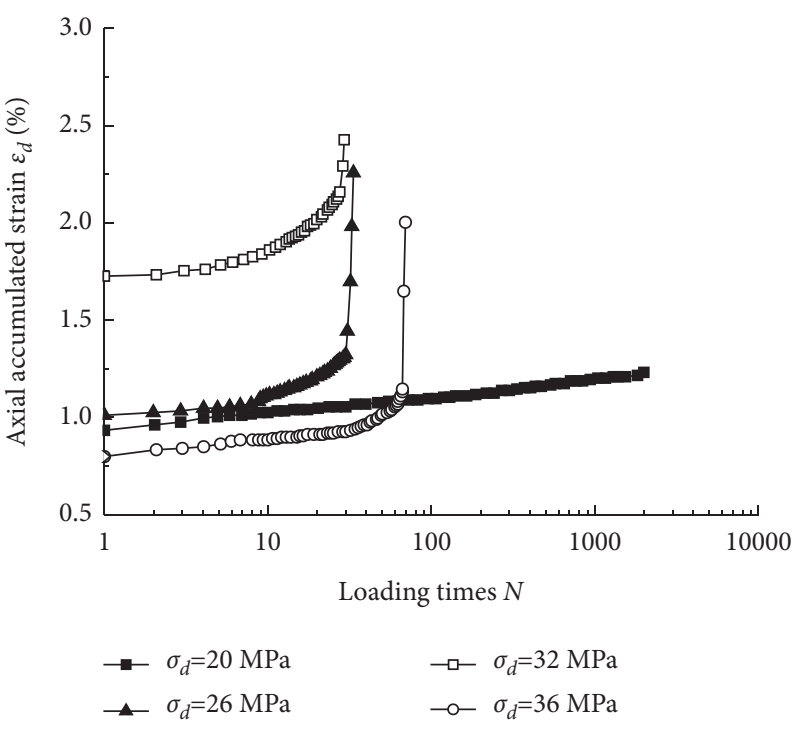

(b)

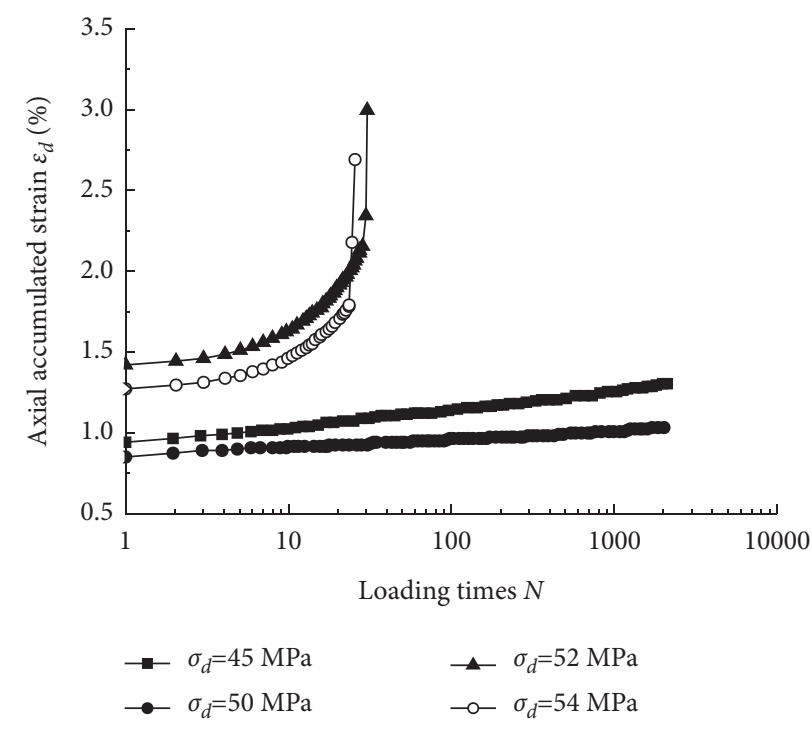

(c)

Figure 3: Degradation of silty mudstone under cyclic loading: (a) $\sigma_{3}=0 \mathrm{MPa}$; (b) $\sigma_{3}=1.5 \mathrm{MPa}$; (c) $\sigma_{3}=3 \mathrm{MPa}$.

strength and indicating that increasing the confining pressure could improve the resistance of the rock sample to cyclic loading.

To study the damage to the mechanical strength of soft rocks by cyclic loading, the minimum and maximum values of dynamic loadings in Table 4 that caused failure were selected with confining pressure to derive the shear strength of soft rocks based on the Mohr-Coulomb criterion, and the results displayed a reduction in cohesion from $2.79 \mathrm{MPa}$ to $1.93 \mathrm{MPa}$ for muddy siltstone and 2.95 $\mathrm{MPa}$ to $1.07 \mathrm{MPa}$ for silty mudstone, illustrated in Figure 6 . With higher $\sigma_{\mathrm{d}}$, the number of cyclic loadings that caused the samples to fail decreased, as shown in Figures 2 and 3, which meant that Figure 6(a) suffered more dynamic loadings than Figure 6(b), and the dynamic loadings were the same in Figure 6(c) as in Figure 6(d). As a consequence, the sample that suffered fewer loading cycles displayed a higher shear strength of cohesion, such as the results shown in Figures 6(b) and 6(d), demonstrating that the shear strength of soft rock decreased as the number of dynamic loadings increased, and the fatigue damage caused by cyclic loading to soft rock increased. Furthermore, the shear strength of the friction angle remained almost the same in Figure 6, indicating that dynamic loading would not damage the shear strength. This assumption of no change in friction angle was also formulated in the laboratory tests $[23,29,30]$. For rocks, the decrease in strength over time resulted from decreased cohesion, while the friction angle remained constant. Consequently, the shear strength degradation under cyclic 


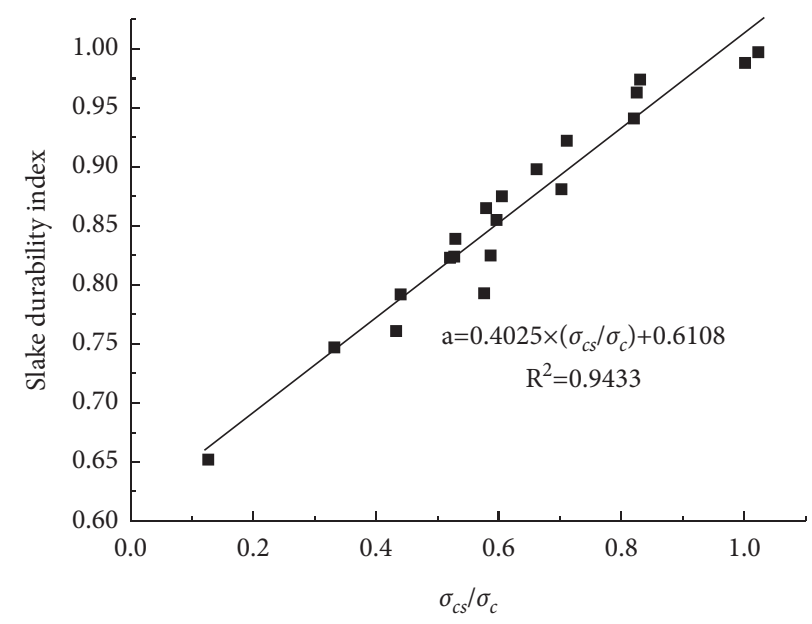

- Measured data — Fitted curve

(a)

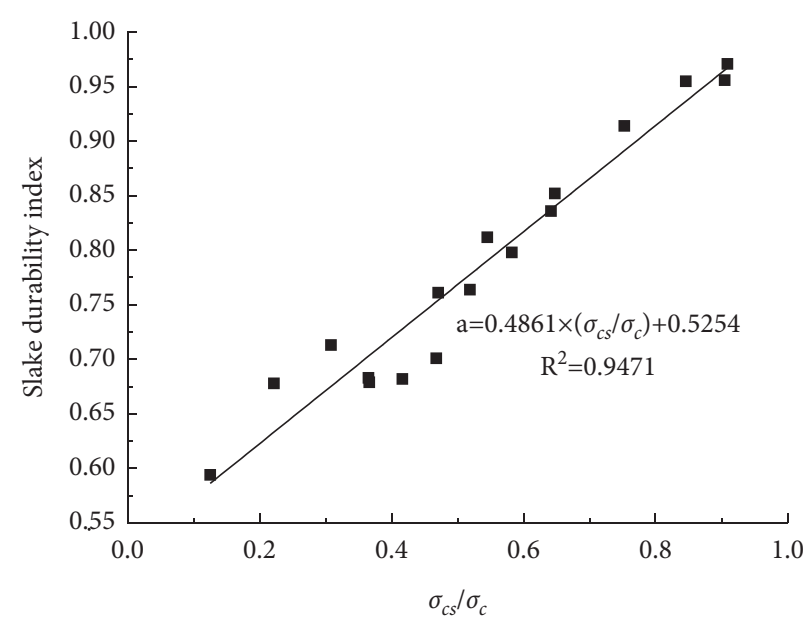

- Measured data

- Fitted curve

FIgURE 4: Relationship between strength damage and slake durability index: (a) muddy siltstone; (b) silty mudstone.

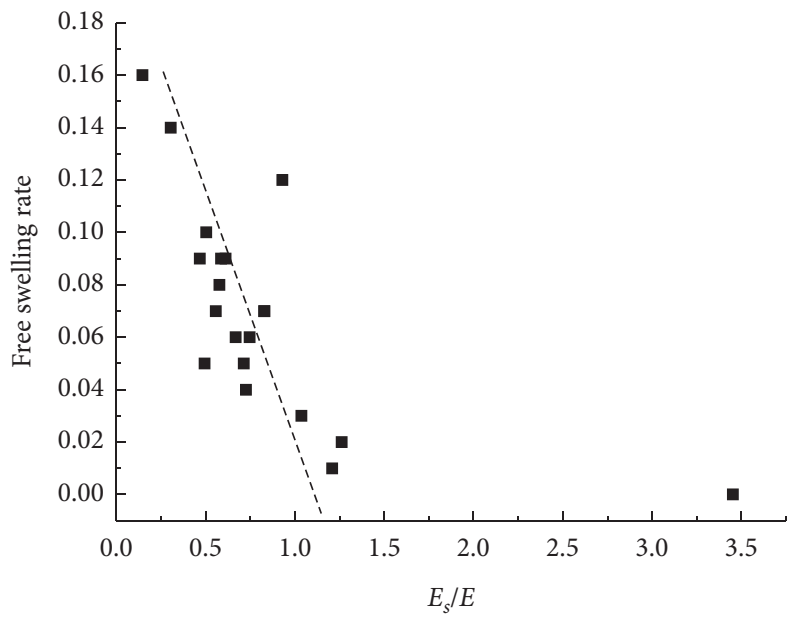

- Measured data

(a)

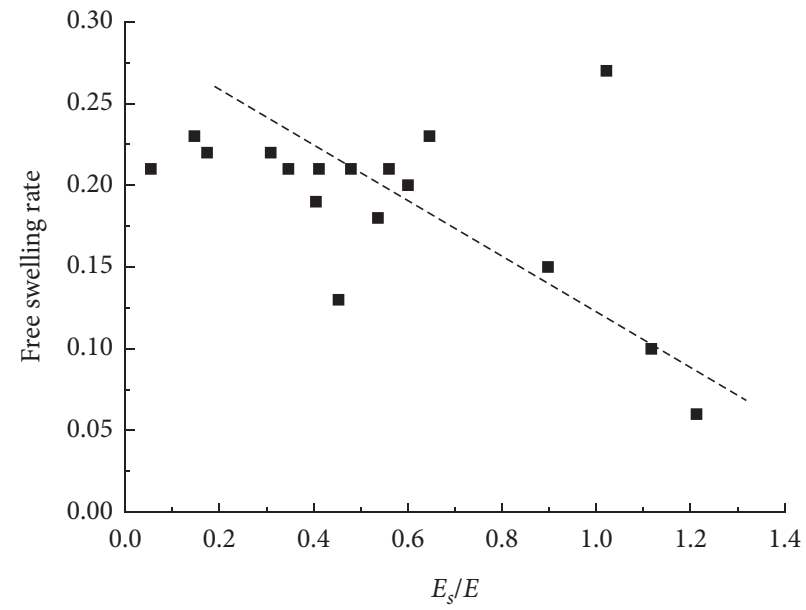

- Measured data

FIGURE 5: Relationship between deformation and free expansion rate: (a) muddy siltstone; (b) silty mudstone.

TABLE 4: $\sigma_{\mathrm{d}}(\mathrm{MPa})$ that leads to a final failure for soft rocks.

\begin{tabular}{lccc}
\hline Soft rock & $\sigma_{3}=0$ & $\sigma_{3}=1.5$ & $\sigma_{3}=3$ \\
\hline Muddy siltstone & $14 ; 14.5 ; 19$ & $32 ; 35 ; 37$ & $51 ; 53 ; 55$ \\
Silty mudstone & $12 ; 16 ; 20$ & $26 ; 32 ; 36$ & $52 ; 54$ \\
\hline
\end{tabular}

loading could be seen as the reduction of cohesion of soft rock, but not the internal friction.

In addition, the dynamic boundary loadings that did not cause the failure of rock samples were stated as $12.5,30$, and $50 \mathrm{MPa}$ for muddy siltstone and 10,20 , and $50 \mathrm{MPa}$ for silty mudstone. These values were used to derive the stiffness of soft rocks under different times of cyclic loading, including the dynamic elastic modulus $E_{d}$ and the dynamic shear modulus $G_{d}$, as shown in Figure 7 . The results illustrated that the dynamic elastic and shear modulus tended to decrease as 

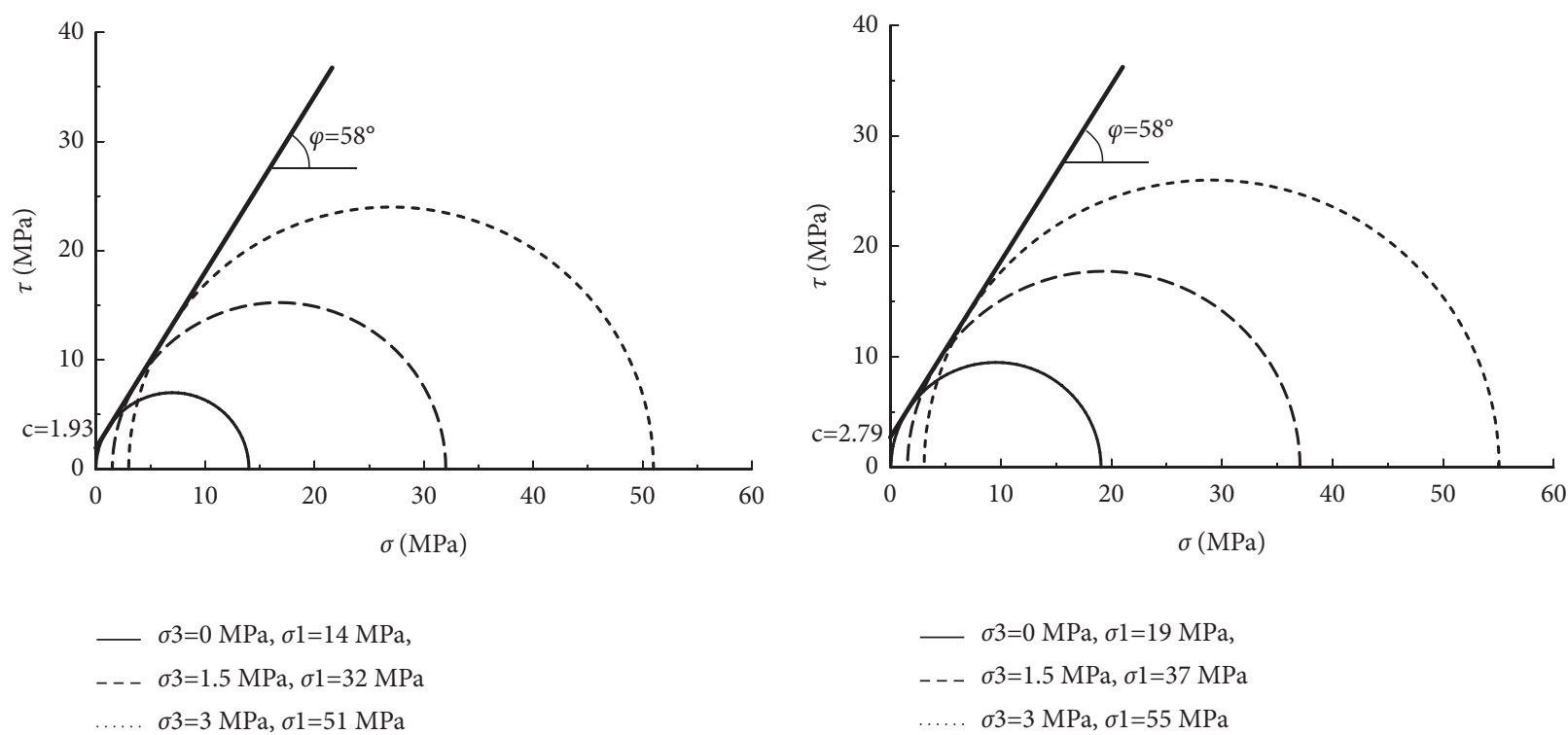

(a)

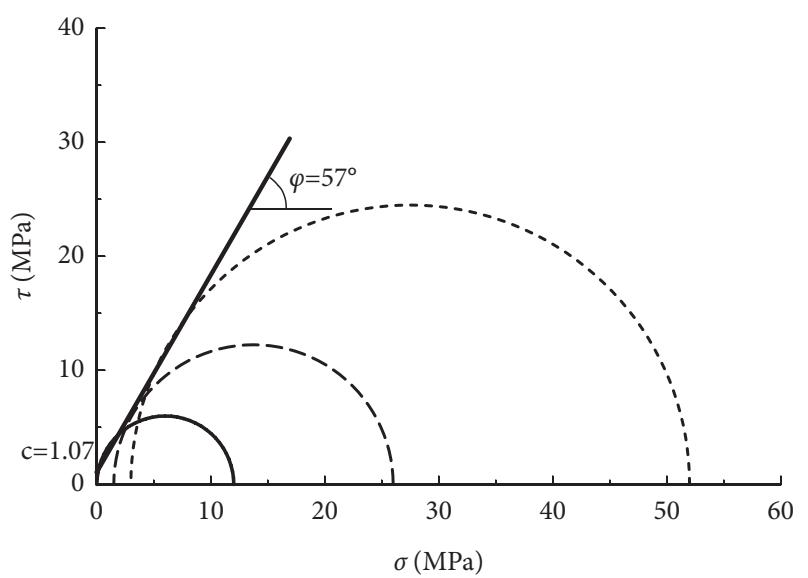

(b)
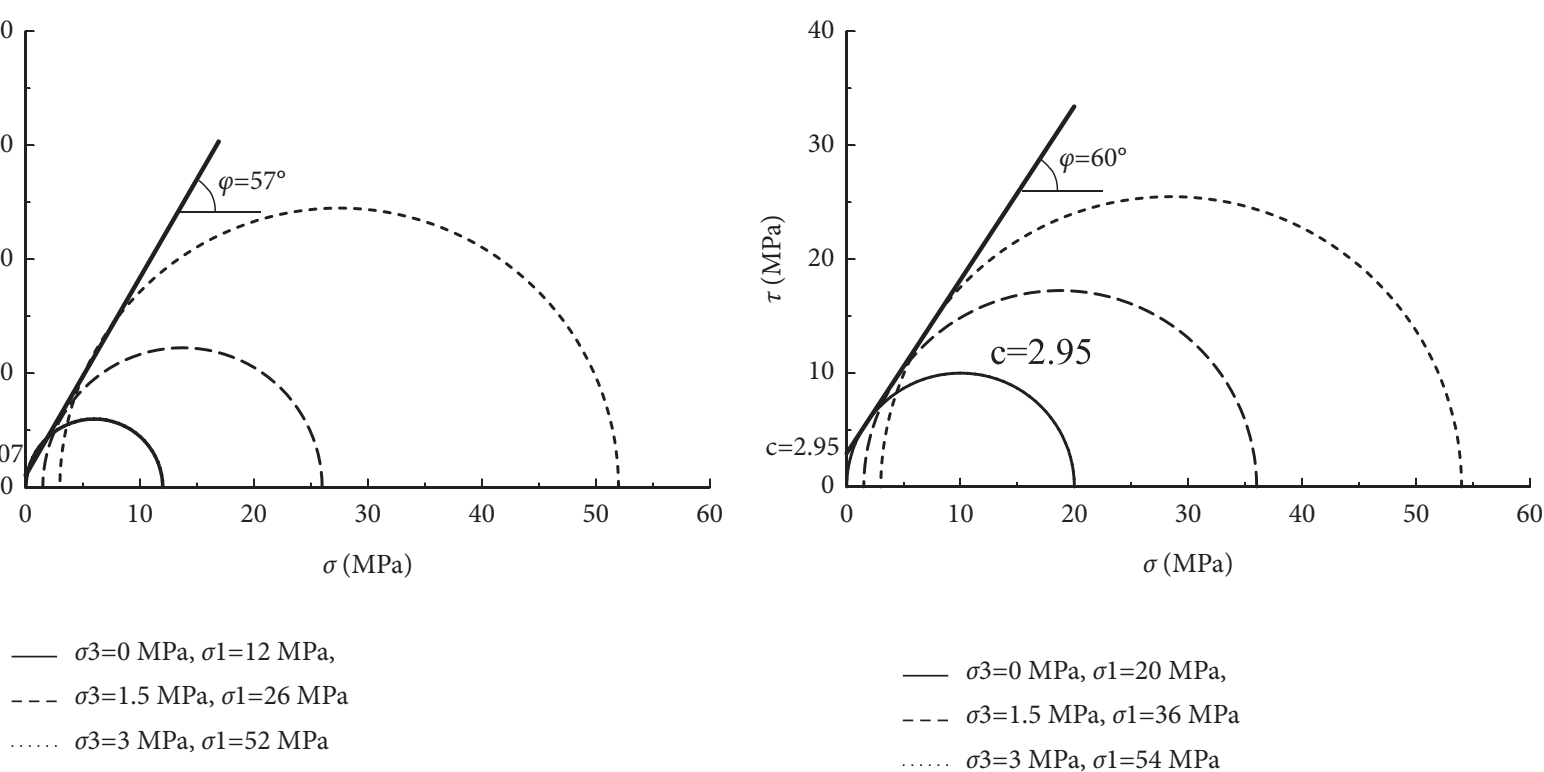

(c)

(d)

Figure 6: Shear strength results based on the Mohr-Coulomb criterion: (a) muddy siltstone with higher N; (b) muddy siltstone with lower $\mathrm{N}$; (c) silty mudstone with higher $\mathrm{N}$; (d) silty mudstone with lower $\mathrm{N}$.

the cyclic loading times increased. Therefore, more serious fatigue damage occurred with increasing loading time. Meanwhile, the greater the confining pressure was, the less reduction of the dynamic parameters acquired. Consequently, a certain amount of fatigue damage would occur under cyclic loading, which was manifested in the macroscopic damage of mechanical properties, such as the reduction of dynamic elastic modulus and dynamic shear modulus. 

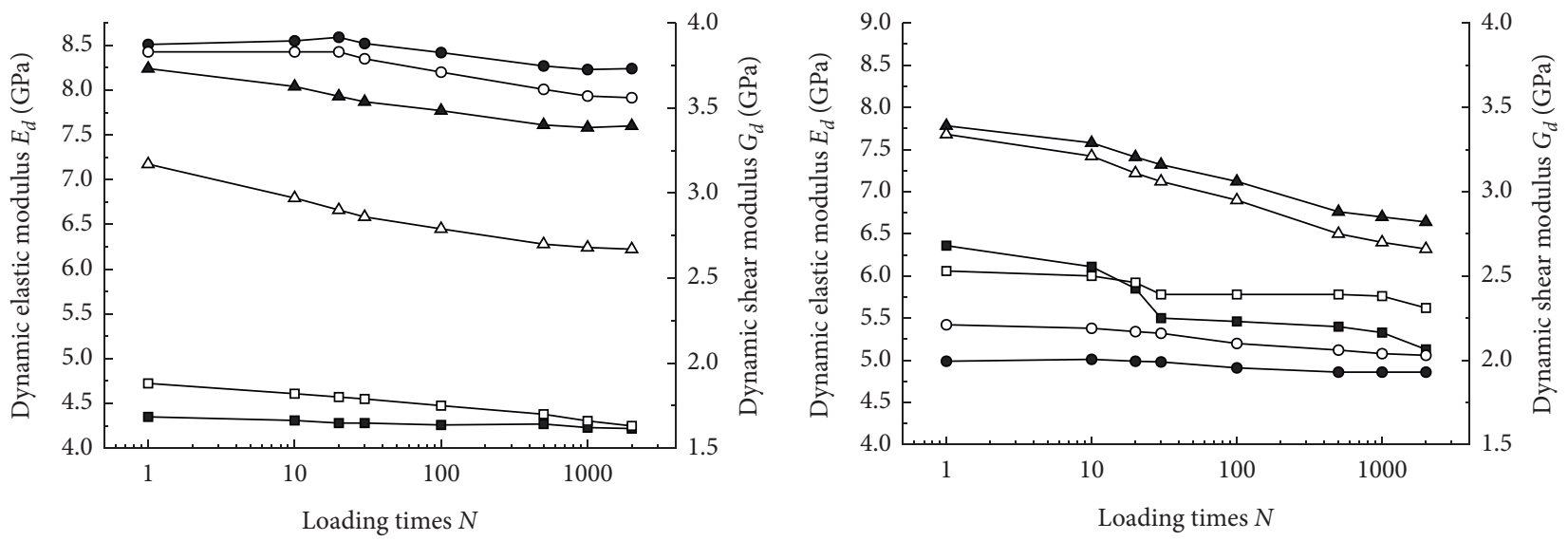

$$
\begin{aligned}
& \rightarrow-E_{d} \sigma_{3}=0 \mathrm{MPa} \\
& \multimap E_{d} \sigma_{3}=1.5 \mathrm{MPa} \\
& \triangle E_{d} \sigma_{3}=3.0 \mathrm{MPa} \\
& \begin{array}{l}
\multimap-G_{d} \sigma_{3}=0 \mathrm{MPa} \\
\multimap G_{d} \sigma_{3}=1.5 \mathrm{MPa} \\
\triangle G_{d} \sigma_{3}=3.0 \mathrm{MPa}
\end{array}
\end{aligned}
$$

(a)

$$
\begin{array}{ll}
\rightarrow E_{d} \sigma_{3}=0 \mathrm{MPa} & \rightarrow-G_{d} \sigma_{3}=0 \mathrm{MPa} \\
\rightarrow E_{d} \sigma_{3}=1.5 \mathrm{MPa} & \multimap-G_{d} \sigma_{3}=1.5 \mathrm{MPa} \\
\neg E_{d} \sigma_{3}=3.0 \mathrm{MPa} & -G_{d} \sigma_{3}=3.0 \mathrm{MPa}
\end{array}
$$

(b)

FIgURE 7: Relationship between loading times and dynamic parameters.

\section{Conclusions}

Based on uniaxial compression and triaxial tests with cyclic loading of soft rocks in southwest China, the deformation characteristics and mechanical properties of rocks subjected to water and cyclic loading were studied. In this paper, the damage performance of water on soft rocks was discussed, and the mechanical properties of fatigue damage of soft rocks were analysed, reaching the following conclusions: Water-rock interactions in soft rocks reduce the strength properties from 25.76 to $21.35 \mathrm{MPa}$ to $17.04-7.07 \mathrm{MPa}$ for muddy siltstone, and from 17.65 to $9.94 \mathrm{MPa}$ to 11.3-5.59 MPa for silty mudstone, which was correlated with disintegration resistance. Meanwhile, soft rocks exhibited a softening phenomenon due to water absorption and rock expansion, exhibiting a decrease in the elastic modulus. With the same circumferential pressure $\sigma_{3}$, the rock sample gradually progressed from undamaged to failing as the cyclic loading $\sigma_{\mathrm{d}}$ increased. During cyclic loading, the shear strength of cohesion decreased from $2.79 \mathrm{MPa}$ to $1.93 \mathrm{MPa}$ for muddy siltstone and $2.95 \mathrm{MPa}$ to $1.07 \mathrm{MPa}$ for silty mudstone, but the friction angle remained almost the same. Additionally, the dynamic elastic modulus and dynamic shear modulus decreased with increasing loading time, demonstrating stiffness degradation in soft rock.

However, a quantitative expression of the relationship between the number of loading cycles and shear strength degradation was not obtained. To understand the foundation deformation and safety under the loading of carrier dynamics, further study will be necessary to establish such a functional relationship.

\section{Data Availability}

The data used to support this study are included within the article.

\section{Conflicts of Interest}

The authors declare that they have no conflicts of interest.

\section{Acknowledgments}

This work was supported by the Science and Technology Foundation of Civil Aviation Flight University of China (J2021-049).

\section{References}

[1] H. F. Deng, M. L. Zhou, J. L. Li, X. S. Sun, and Y. L. Huang, "Creep degradation mechanism by water-rock interaction in the red-layer soft rock," Arabian Journal of Geosciences, vol. 9, no. 12, pp. 601-612, 2016.

[2] M. C. He, "Latest progress of soft rock mechanics and engineering in China," Journal of Rock Mechanics and Geotechnical Engineering, vol. 6, pp. 165-179, 2014.

[3] Q. B. Meng, L. J. Han, W. G. Qiao, D. G. Lin, and L. Yang, "Mechanism of rock deformation and failure and monitoring analysis in water-rich soft rock roadway of western China," Journal of Coal Science and Engineering, vol. 18, no. 3, pp. 262-270, 2012.

[4] Z. Dai, J. Guo, F. Yu, Z. Zhou, and J. Li, "Long-term uplift of highspeed railway subgrade caused by swelling effect of red-bed mudstone: case study in Southwest China," Bulletin of Engineering Geology and the Environment, vol. 80, pp. 4855-4869, 2021.

[5] P. Mi Evi and G. Vlastelica, "Estimation of embankment settlement caused by deterioration of soft rock grains," Bulletin of Engineering Geology and the Environment, vol. 78, no. 3, pp. 1843-1853, 2019.

[6] V. Eeckhout, "The mechanisms of strength reduction due to moisture in coal mine shales," International Journal of Rock Mechanics and Mining Sciences \& Geomechanics Abstracts, vol. 13, no. 2, pp. 61-67, 1976.

[7] Y. Pan, G. Wu, Z. M. Zhao, and L. He, "Analysis of rock slope stability under rainfall conditions considering the water-induced weakening of rock," Computers and Geotechnics, vol. 128, Article ID 103806, 2020. 
[8] F. L. Pellet, M. Keshavarz, and M. Boulon, "Influence of humidity conditions on shear strength of clay rock discontinuities," Engineering Geology, vol. 157, pp. 33-38, 2013.

[9] B. Vásárhelyi, "Statistical analysis of the influence of water content on the strength of the miocene limestone," Rock Mechanics and Rock Engineering, vol. 38, no. 1, pp. 69-76, 2005.

[10] B. Vásárhelyi and P. Ván, "Influence of water content on the strength of rock," Engineering Geology, vol. 84, pp. 70-74, 2006.

[11] P. Delage and D. Tessier, "Macroscopic effects of nano and microscopic phenomena in clayey soils and clay rocks," Geomechanics for Energy and the Environment, vol. 27, pp. 100-177, 2021.

[12] D. L. Olgaard, J. Urai, L. N. Dell'Angelo, R. Nüesch, and G. Ingram, "The influence of swelling clays on the deformation of mudrocks," International Journal of Rock Mechanics and Mining Sciences, vol. 34, pp. 231-235, 1997.

[13] L. L. Wang, D. S. Yang, R. W. Yang, and S. Chanchole, "Investigating the mechanical behavior of shale: a micro-scale approach," Journal of Natural Gas Science and Engineering, vol. 36, pp. 1295-1302, 2016.

[14] N. Zhang, M. C. He, and P. Y. Liu, "Water vapor sorption and its mechanical effect on clay-bearing conglomerate selected from China," Engineering Geology, vol. 141-142, pp. 1-8, 2012.

[15] X. L. Lai, S. M. Wang, W. M. Ye, and Y. J. Cui, "Experimental investigation on the creep behavior of an unsaturated clay," Canadian Geotechnical Journal, vol. 51, no. 6, pp. 621-628, 2014.

[16] C. Ma, H. B. Zhan, W. M. Yao, and H. Z. Li, "A new shear rheological model for a soft interlayer with varying water content," Water Science \& Engineering, vol. 11, no. 2, pp. 47-54, 2018.

[17] O. O. R. Famiyesin, T. G. Davies, and A. H. C. Chan, "Numerical modelling of cyclic loading on reinforced unbound pavements," Computers \& Structures, vol. 68, no. 1, pp. 231-249, 1998.

[18] M. M. He, Z. Q. Zhang, and N. Li, "Experimental investigation and empirical model to determine the damping and shear stiffness properties of soft rock under multistage cyclic loading," Soil Dynamics and Earthquake Engineering, vol. 147, Article ID 106818, 2021.

[19] D. Ling, Y. Zhao, B. Huang, F. Zhang, and Y. Zhou, "Analysis of dynamic stress path in inhomogenous subgrade under moving aircraft load," Soil Dynamics and Earthquake Engineering, vol. 111, pp. 65-76, 2018.

[20] K. Akai and Y. Ohnishi, "Strength and deformation characteristics of soft sedimentary rock under repeated and creep loading," in Proceedings of the 5th congress International Society for Rock Mechanics, pp. A121-A124, Melbourne, Australia, 1983.

[21] Y. Liu and F. Dai, "A review of experimental and theoretical research on the deformation and failure behavior of rocks subjected to cyclic loading," Journal of Rock Mechanics and Geotechnical Engineering, 2021.

[22] Z. Maqsood, J. Koseki, Y. Miyashita, J. Xie, and H. Kyokawa, "Experimental study on the mechanical behaviour of bounded geomaterials under creep and cyclic loading considering effects of instantaneous strain rates," Engineering Geology, vol. 276, Article ID 105774, 2020.

[23] R. Pytlik and S. Van Baars, "Shear strength and stiffness degradation of geomaterials in cyclic loading," Soils and Rocks, vol. 39, no. 3, pp. 273-283, 2016.

[24] M. N. Bagde and V. Petroš, "Fatigue properties of intact sandstone samples subjected to dynamic uniaxial cyclical loading," International Journal of Rock Mechanics and Mining Sciences, vol. 42, no. 2, pp. 237-250, 2005.
[25] L. Guo, Y. Cai, R. Jardine, Z. Yang, and J. Wang, "Undrained behaviour of intact soft clay under cyclic paths that match vehicle loading conditions," Canadian Geotechnical Journal, vol. 55, pp. 90-106, 2017.

[26] G. A. Miller, S. Y. Teh, D. Li, and M. M. Zaman, "Cyclic shear strength of soft railroad subgrade," Journal of Geotechnical and Geoenvironmental Engineering, vol. 126, no. 2, pp. 139$147,2000$.

[27] K. Bian, J. Liu, W. Zhang, X. Zheng, S. Ni, and Z. Liu, "Mechanical behavior and damage constitutive model of rock subjected to water-weakening effect and uniaxial loading," Rock Mechanics and Rock Engineering, vol. 52, no. 1, pp. 97-106, 2019.

[28] Astm, Standard Test Method for Slake Durability of Shales and Similar Weak Rocks, pp. D4644-D4648, ASTM, West Conshohocken, PA, USA, 2008.

[29] N. Brantut, M. J. Heap, P. G. Meredith, and P. Baud, "Timedependent cracking and brittle creep in crustal rocks: a review," Journal of Structural Geology, vol. 52, no. 5, pp. 17-43, 2013.

[30] S. Vyalov, Rheologic Principles of Soil Mechanics (In Russian), Vysshaya Shkola, Moscow, Russia, 1978. 